\title{
DE CADÍ A ALCALDE MAYOR. LA ÉLITE JUDICIAL MUDÉJAR EN EL SIGLO XV (II)
}

\author{
ANA ECHEVARRÍA ARSUAGA
}

UNED, Madrid *

\section{El alcalde mayor de moros en el siglo XV y la pervivencia de las estructuras islámicas}

Aunque se ha propuesto la figura de Muhammad Alfajar como «primer alcalde mayor efectivo de los moros» ${ }^{1}$, creemos que ha quedado suficientemente demostrada la continuidad del cadiazgo en la alcaldía mayor desde época islámica hasta el siglo XV, a pesar de los vacíos existentes en la documentación. Debería cuestionarse también el que el alcalde mayor de Murcia fuera necesariamente el de todo el reino, lo mismo que Alí Xarafí ${ }^{2}$, alcalde de los moros de Alcalá de Henares en 1351 pudo ser alcalde sólo de esta población. La continuidad del cargo a nivel general de todo el reino es más difícil de demostrar, aunque desde que hace su aparición en las fuentes tiene casi las mismas características que el cadiazgo de la comunidad islámica tradicional. La primera mención específica a un alcalde mayor para todas las aljamas de moros del reino de Castilla coincide con un «proceso de centralización de las estructuras comunales», en palabras de Castaño $^{3}$, que se produjo tanto en las aljamas judías como en las mu-

* Este trabajo ha sido realizado dentro del proyecto financiado por la Comunidad Autónoma de Madrid «Implicaciones sociales y políticas de la conversión en la Castilla del siglo XV», adscrito al Departamento de Historia Medieval, Moderna y Ciencias y Técnicas Historiográficas de la UNED de Madrid.

1 Torres Fontes, J., «El alcalde mayor de las aljamas de moros del reino de Castilla», Anuario de Historia del Derecho Español (1962), 149.

2 Torres Fontes, J., «El alcalde mayor», 157; Molénat, J. P., «Une famille de l'élite mudéjare de la Couronne de Castille: les Xarafi de Tolède et Alcalá de Henares», Mélanges Louis Cardaillac. Études réunies et préfacées par Abdeljelil Temimi, Zaghouan, 1995, 2, 768.

3 Castaño, J., «Tensiones entre las comunidades judías y la monarquía en Castilla, c. 1447-1474: el nombramiento del juez mayor de las aljamas», en Creencias y culturas.

Al-Qanțara XXIV, 2 (2003) 273-290 
sulmanas desde comienzos del siglo XV. En ambos casos se intenta establecer una estructura jerárquica, a la cabeza de la cual se encontrarían, respectivamente, un rab mayor de la corte y un alcalde mayor de las aljamas de moros. El sistema, similar al de los concejos cristianos, contaba con tres niveles: la comunidad al completo se reunía raramente; más a menudo lo hacía un consejo de adelantados o viejos, de número variable; finalmente, un cuerpo ejecutivo más reducido hacía aplicar las decisiones ${ }^{4}$. El escalón más elevado, el de rab o alcalde mayor, tenía acceso directo a la corte y formaba parte de la oligarquía, por lo que se consideraban en el deber de utilizar su posición en favor de sus respectivas comunidades. A cambio, debían gozar de una posición privilegiada también dentro de su propio grupo ${ }^{5}$.

Una vez que hemos analizado la trayectoria de los hombres y las familias que desempeñaron en algún momento la alcaldía mayor del reino castellano, es el momento de analizar con detenimiento hasta qué punto este cargo judicial seguía respondiendo a las características de su antecedente, el cadí islámico, y de qué forma se manifestaban las rupturas con el sistema establecido bajo gobierno musulmán, dictadas sobre todo por la presencia de la autoridad cristiana en la cúspide del poder, y por la reorganización de las aljamas del reino bajo consignas cristianas. El nombramiento de Abrahen Xarafí da más detalles sobre el ejercicio de la alcaldía de lo que hacían documentos anteriores, confirmando que sus atribuciones coinciden con las del cadí islámico, tal como fueron definidas por Tyan ${ }^{6}$.

Cristianos, judios y musulmanes en la España medieval (ed. C. Carrete Parrondo y A. Meyuhas Ginio), Salamanca, 1998, 11.

${ }_{4}$ Kriegel, M., Les juifs à la fin du Moyen Age dans l'Europe méditérranéenne, Paris, $1979,112,128$.

${ }_{5}$ Kriegel, M., Les juifs à la fin du Moyen Age,134.

6 AGS, RGS, enero, 1475 , f. 362, Cit. Torres Fontes, J., «El alcalde mayor», 172-175. Para el oficio en época islámica, Tyan, E., Histoire de l'organisation judiciaire en pays d'Islam, Lyon, 1943, II, 3-13; en Granada, Calero Secall, M. I., «La justicia. Cadíes y otros magistrados», en El reino nazari de Granada, Historia de España Menéndez Pidal (coord. M. J. Viguera), Madrid, 2000, VIII.3, 406-408. 


\section{Factores de continuidad}

\section{Designación para el cargo}

En cuanto a las formas de elección del alcalde mayor, no podemos hablar de «intervencionismo real» ${ }^{7}$, pues era precisamente el gobernante islámico (sultán o rey) el que nombraba al qāọī al-qūdāt. Así ocurría en la Granada nazarí, donde el qāại al-yam $\bar{a}^{c} a$ era designado por el monarca y no tenía capacidad para nombrar a otros jueces, excepto a algún delegado suyo, perdiendo gran parte de su poder político anterior ${ }^{8}$. Gracias a los testimonios de un pleito entre Lorca y Vera por las villas de Huércal y Overa sabemos que era vox populi que los cadíes «yban por las çiudades, villas e lugares del dicho rreino de Granada a usar los dichos sus oficios, pero que ninguna ciudad, villa ni lugar del dicho rreino de Granada en el dicho tiempo de moros podía ni pudo nombrar cadí ni alcaide ni caudillos ni alguacil, mas de solamente el dicho rrei moro» ${ }^{9}$. En teoría, esta prerrogativa correspondía también al monarca cristiano respecto al alcalde mayor de las aljamas y el rab mayor de la Corte, aunque en la práctica generó importantes tensiones de los musulmanes y judíos con el rey ${ }^{10}$.

En el caso musulmán, eso no supone que la aljama no tenga nada que decir al respecto: es muy posible que los notables de las aljamas tuvieran una especie de derecho de presentación de candidatos al rey lo mismo que en el caso judío y, una vez nombrado, tenían que aceptar formalmente a la persona, en una ceremonia pública de toma de posesión ${ }^{11}$, a juzgar por la forma en que se expresan los documentos.

\footnotetext{
${ }^{7}$ Molénat, J. P. «À propos d'Abrahen Xarafi: les alcaldes mayores de los moros de Castille au temps des Rois Catholiques», en Actas del VII Simposio Internacional de Mudejarismo (A partir de ahora, ASIM), Teruel, 1999, 181-182 también discute este punto, sostenido por Torres Fontes, J., «El alcalde mayon», 161; Carmona, A., «Le malékisme et les conditions requises pour l'exercice de la judicature», Islamic Law and Society, 7, 2 (2000), 123.

${ }^{8}$ Calero Secall, M. I., «Rulers and Qädīs: Their Relationship during the Nașrid Kingdom», Islamic Law and Society 7, 2 (2000), 238.

9 Arcas Campoy, M., «Noticias sobre el cadiazgo en los últimos años del reino nazarí: la frontera entre Murcia y Granada», Revista del Centro de Estudios Históricos de Granada y su reino, 6 (1992), Segunda Época, 206.

10 Castaño, J.: «Tensiones entre las comunidades judías», 12. El paralelismo entre las estructuras de musulmanes y judíos ya fue comentado por Gutwirth, E., «Hispano-Jewish Attitudes to the Moors in the Fifteenth Centuryn, Sefarad (1989), 238-239. 397.

11 Sobre la investidura del cadí en Granada, ver Calero Secall, M. I., «La justicia»,
} 
En este sentido, es muy reveladora la fatwà de Abū Muhammad ${ }^{\mathrm{c}} \mathrm{Abd}$ Allāh al- ${ }^{\mathrm{A}} \mathrm{Abdūs} \overline{\text {, }}$ muftí de Fez en torno a 1442-45, que define en estos términos la figura del cadí en territorio mudéjar ${ }^{12}$ :

\begin{abstract}
Respecto al cadí que se encuentra allí, si la aljama de los musumanes de ese lugar le elige, su cadiazgo es lícito, lo mismo que la práctica ( ${ }^{c} \mathrm{amal}$ ) basada en su firma, que verifica la validez, si es seguro que ellos le nombraron y que ésa es su escritura, porque la comunidad ejerce todo el poder en caso de que el sultán esté impedido. En caso de que el gobernante de los cristianos le nombre, ni su nombramiento ni su veredicto ( $h u k m)$ será aceptado a no ser que la aljama de los musulmanes lo acepte de buen grado, y no bajo presión. En ese caso su veredicto es aceptable como si hubiera sido elegido por ellos en primera instancia por su propia voluntad, y esto lo convierte en su elección, y no el nombramiento [de la autoridad cristiana].
\end{abstract}

$Y$ es precisamente en los casos en los que no se realiza esta segunda condición para el nombramiento del alcalde cuando la comunidad recurre directamente a la persona del rey o a su audiencia, única instancia de derecho superior al cadí, y que debe juzgar su caso también de acuerdo con la legislación islámica:

E la sentençia o sentençias, mandamiento o mandamientos que fueren apelados de vos el dicho don Abrahen Xarafi mi alcalde mayor de las aljamas vengan e parescan ante mi en el mi consejo para que ende se determine e libre segund la dicha vuestra ley e Açuna de moros ${ }^{13}$.

Hasta qué punto consideran los mudéjares a los alcaldes como representantes de la autoridad cristiana y no de su propia comunidad, se pone de manifiesto en numerosos documentos de protesta por la actuación de los alcaldes, y la petición en determinados casos de jueces cristianos que juzguen las causas de algunos mudéjares que consideran sus intereses lesionados por su propio alcalde.

La ley islámica malikí, tal como ha demostrado Carmona ${ }^{14}$, tenía un concepto bastante claro de las cualidades que se debían exigir a un magistrado, y por esta razón, y no por la «intromisión» del poder real, es por lo que la aljama de Valencia se debió de quejar a Pedro el Ceremonioso en 1337, diciendo que los cadíes eran elegidos por el batlle y

12 Traducido a partir de Wiegers, G., Islamic Literature in Spanish and Aljamiado. Yça of Segovia, his Antecedents and Successors, Leiden, 1994, 86-87. La cursiva es mía.

13 ARCV, RCE, c. 39, 7.

14 Carmona, A., "La figura del cadí en los textos jurídicos malikíes», Actas del II Congreso Internacional Encuentro de las Tres Culturas, Toledo, 1985, 89-96 y el ya citado «Le malékisme». 
la corona sin tener en cuenta los preceptos del Islam, y en detrimento de la comunidad. A partir de entonces se decidió que los ancianos de la aljama serían consultados sobre el conocimiento y la conveniencia de los posibles nominados, antes de otorgar el cargo definitivamente. Este consejo de los ancianos estaba formado por los hombres más influyentes del lugar. Son los «buenos e viejos onbres» de los textos de las capitulaciones, o los «viejos» de la documentación ${ }^{15}$. Cuando se pretendió castellanizar la organización, éstos debieron convertirse en los regidores del concejo. Con la diferencia de que este nuevo estatus les permitiría a los reyes y nobles nombrarlos directamente.

El supuesto nombramiento de Abrahen Xarafí como alcalde mayor de las aljamas de Aranda, Ávila, y todas las demás que fuesen cayendo bajo la jurisdicción de la princesa Isabel, en 1473, presenta algunas irregularidades importantes respecto a la designación habitual de los alcaldes, pues la princesa se arroga un derecho que no tiene. Como acabamos de ver, sólo al rey y en algún caso a los maestres de las órdenes militares, correspondía nombrar alcalde mayor de las aljamas del reino, y a las comunidades la designación de los alcaldes mayores de cada ciudad, a no ser que el alcalde mayor designare lugartenientes suyos.

Queda por explicar la aparente despreocupación y falta de comprobaciones de los Reyes Católicos a la hora de nombrar o confirmar a los distintos alcaldes. En primer lugar, hay que considerar que para los reyes cristianos la multiplicación de los alcaldes no constituye ningún problema legal, y puede justificarse por la necesidad de jueces especializados en derecho islámico ${ }^{16}$, como señaló el rey Martín I de Aragón en 1399. En un momento dado, y al igual que con sus súbditos cristianos, los reyes contemplan el cargo de alcalde mayor de las aljamas como una distinción que pueden otorgar a sus fieles. Esta política ya se había seguido en Aragón durante el siglo XIV, incluso con favoritos cristianos, y pudo influir en la despreocupación de Fernan-

15 Sobre su origen, ver Febrer Romaguera, M. V., «Antecedentes y configuración de los consejos de viejos en las aljamas de moros valencianas», ASIM V, Teruel, 1991, 147-169.

16 Con motivo del nombramiento de Hamete Alcaudí como cadí general de sus reinos, sin perjuicio de Alí de Bellvís. ACA, C, reg. 2230, f. 150 r. Cit. Ferrer i Mallol, M. $\mathrm{T}$., La frontera amb l'Islam en el segle XIV. Cristians $i$ sarrains al País Valencià, Barcelona, 1988, 21, n. 15. 
do ${ }^{17}$. Además de Xarafi, hay otros alcaldes que acceden al puesto en premio a servicios prestados a Isabel y Fernando en sus aspiraciones al trono. La conveniencia política y los deseos arbitrarios del monarca eran también la norma en Granada, donde sucesivos cadíes supremos fueron destituidos en el siglo XV según dictaban los avatares del pequeño reino ${ }^{18}$.

Pero los orígenes de esta política pueden encontrarse también en la dispersión de los territorios de la corona y la diversidad de estatutos y organización de los musulmanes de los distintos reinos. Ante esta diversidad, los Reyes Católicos optarían, como es común en ellos, por la imposición del poder real como último referente, designando no sólo a los alcaldes mayores del reino, como les correspondía, sino también a sus lugartenientes en distintas ciudades, muchas veces sin cerciorarse de si el cargo era duplicado, por encontrarse los reyes lejos de la administración central y estar delegados sus poderes en su audiencia o su consejo. Así se originan los numerosos pleitos que hemos ido mencionando a lo largo de este trabajo. Quizá el primero planteado ante don Fernando fue la protesta de Muça de Almatar de Calatayud ante el bayle Guillem de Peralta, reclamando sus derechos como alcalde de esa ciudad, en vez de Omar el Ruvio, que habría sido nombrado por el propio Fernando. Muça alegaba precisamente que poseía la alcaldía «por privilegio a el otorgado por el alcadí general de los regnos de Aragón, Valencia e prinçipado de Catalunya, el qual tiene poder segunt la magestat del dito senyor Rey de Siçilia, manifiesta tener poder de crear lugartenient» ${ }^{19}$.

\section{Extracción social}

Según el derecho malikí, para garantizar la imparcialidad del cadí se prefería que fuera una persona con medios de vida suficientes, para que fuera menos gravoso a la comunidad y para que no se sintiera tentado a apropiarse de los bienes que gestionaba ${ }^{20}$. Una buena situación

17 Boswell, J., The Royal Treasure. Muslim Communities under the Crown of Aragon in the Fourteenth Century, New Haven, 1977, 81.

18 Calero Secall, M. I., «Rulers and Qādīs», 239-240.

19 García Marco, F. J., Las comunidades mudéjares de Calatayud en el siglo XV, Calatayud, 1993, 246-247.

20 Carmona, A., «La figura del cadí», 95. 
social le proporcionaba también el acceso a los contactos sociales que podían facilitar su nombramiento por parte del monarca ${ }^{21}$. Además, un cadí o alcalde, según el derecho malikí, debía ser previamente alfaquí, es decir, conocedor del derecho islámico ${ }^{22}$. Como hemos visto por la trayectoria personal y profesional de las distintas familias mudéjares que ejercieron la alcaldía mayor de las aljamas, todas ellas cumplían estos requisitos.

Aunque la actuación del alcalde era en principio gratuita, se toleraba que percibiese una remuneración procedente de partidas determinadas del tesoro público, o de las gratificaciones que le otorgara el soberano ${ }^{23}$. Recogiendo este espíritu, el cargo se concede con «todos los derechos e salarios e otras cosas al dicho oficio de alcaldía mayor anexas». No se especifica si este salario procedía de la administración de la casa y corte del rey, o si era la comunidad mudéjar la encargada de pagarlo. Desde luego, en las nóminas de quitaciones del rey no aparece ninguna partida destinada a pagar a los alcaldes mayores de las aljamas, aunque como ya hemos dicho, varios de ellos aparecen pagados por otros conceptos.

Otra forma de remuneración muy extendida y especialmente importante cuando se trataba de familias con negocios propios era la exención de cargas tributarias. Esas concesiones despertaban suspicacias y animosidad entre los miembros de las aljamas ${ }^{24}$, que protestaban ante el rey del trato de favor que recibían los alcaldes mayores (en muchos casos locales), sobre todo cuando los repartimientos y los castellanos de oro fueron convirtiéndose en especialmente gravosos con motivo de la guerra de Granada.

${ }^{21}$ La situación es la misma a este respecto en Granada y Castilla. Calero Secall, M. I., «La justicia», 397-399.

22 Carmona, A., «La figura del cadí», 94.

${ }^{23}$ Carmona, A., «Le malékisme», 131; Peláez Portales, D., La administración de justicia en la España musulmana, Córdoba, 1999, 89-90. En Aragón también cobraba unos 200 sueldos en 1484, según Meyerson, M., op.cit., 102.

${ }^{24}$ AGS, Registro General del Sello, septiembre 1484, f. 156. 


\section{Atribuciones del cargo}

\subsection{Ejercicio de la justicia ordinaria}

La justicia ordinaria acompañada de un papel coercitivo importante tal como propugnaba la escuela malikí, se mantiene en el alcalde mayor de moros al dársele jurisdicción civil y criminal dentro de las aljamas, y autorizándole a dar sentencia de acuerdo con «la ley e açunna de moros». Por ello se ordena a todos los musulmanes:

\footnotetext{
que vayan e parescan ante vos, el dicho don Abraham Xarafi, como ante nuestro alcalde mayor e ante vuestros logares tenientes, a vuestros llamamientos e enplazamientos e abdiençias a los plazos e so las penas que les posyeredes e mandaredes poner de nuestra parte; las quales nos por la presente les ponemos e avemos por puestas,
}

y se le dan amplios poderes ejecutivos, en los que estará auxiliado por los alguaciles y ejecutores del rey. El poder de emitir normas de jurisprudencia en los títulos de su competencia va implícita al reconocimiento de todas las prerrogativas que tuvo el oficio de alcalde mayor en los tiempos pasados.

\subsection{Capacidad de actuar como notario en cuestiones legales}

El alcalde tiene además, por herencia directa del cadí, una función notarial: tiene el poder de redactar y legalizar actos jurídicos por escrito. Es a esta capacidad a la que hace referencia la frase «con la escrivania a el adjunta», que aparece en el nombramiento de Xarafí. La importancia económica de este cargo anejo ya fue destacada por Torres Fontes.

\subsection{Elección de delegados}

Entre las atribuciones del alcalde, lo mismo que para el cadí, estaba la capacidad de designar lugartenientes para oír los recursos de alzada, para inspeccionar o trasladarse a cualquier comarca o villa y para destituir o cambiar a los jueces menores ${ }^{25}$. Asistimos así a dos tendencias que se dan simultáneamente: mientras que la centraliza-

25 Torres Fontes, J., «El alcalde mayor», 158. 
ción en la justicia musulmana ejercida por un solo alcalde mayor es más intensa de lo que fuera nunca desde los reinos de Taifas hasta época almohade - pues una sola familia de una ciudad dada controla los resortes judiciales de las aljamas más importantes del reino-, se desencadenan una serie de fuerzas centrífugas en el ejercicio del poder, pues el alcalde mayor se ve obligado a nombrar a sus representantes en aquellas ciudades a las que no puede desplazarse constantemente.

Así lo demuestra la carta escrita por Mahomad ibn Yusuf Alcaybçi o Alcayçi, de Toledo, al concejo de Sepúlveda ${ }^{26}$, que presenta lo que van a ser las líneas maestras de la actuación de los alcaldes mayores a lo largo de todo este siglo, basadas siempre en la institución del cadiazgo islámico, pero con algunas variaciones específicas producidas por la superposición de las autoridades cristianas.

En primer lugar, el alcalde mayor tiene la capacidad jurídica de nombrar a jueces delegados o sustitutos, que responden a la categoría del $n \bar{a}$ i $i b$ nombrado por el cadí islámico. Según ha comprobado Calero Secall para Granada, los sustitutos podían ser de dos tipos: «aquellos que reemplazan al cadí en su propia sede por motivos de enfermedad o ausencia temporal del titular, y el que ejerce en su nombre en lugares alejados de la sede por ser ésta de gran extensión o por las dificultades y hostilidad del terreno ${ }^{27} \gg$. El nombramiento de estos cargos fomentaba la creación de redes de clientela entre los alcaldes mayores, lo mismo que había ocurrido entre los cadíes andalusíes de distintas épocas ${ }^{28}$. En este caso nos encontramos ante un lugarteniente del segundo tipo, puesto que la sede del alcalde mayor era la ciudad de Toledo y la villa de Sepúlveda se halla bastante alejada, y en el área de influencia de Segovia, que a su vez depende también de la alcaldía principal. La extensión de las circunscripciones correspondientes a las alcaldías podía ser muy variable, y dependía de las ciuda-

${ }^{26}$ Publicada por Sáez, E., Colección diplomática de Sepúlveda, Pamplona, 1956, 534-538; Cit. Torres Fontes, J., «El alcalde mayor», 153-155.

${ }_{27}$ Calero Secall, M. I., «El juez delegado $(n \bar{a} ' i b)$ del cadí en el reino nazarí de Granada», Andalucía Islámica, 4-5 (1983-86), 165. Esto explica el «reparto territorial entre dos o más alcaldes mayores de los moros» que señalara Molénat, J.-P., «À propos d'Abrahen Xarafì», 181.

${ }_{28}$ Ver, por ejemplo, Rodríguez Mediano, F., «Instituciones judiciales: cadíes y otras magistraturas», en El retroceso territorial de al-Andalus. Almorávides y Almohades, Historia de España Menéndez Pidal (coord. M. J. Viguera),VIII.2, 179-181. 
des/aljamas importantes que hubiera en una zona determinada, así como de la dificultad de las comunicaciones, especialmente en las zonas más montañosas de la Península. El cargo se convertía así en un oficio casi itinerante. Los estudios que ha realizado Arcas Campoy 29 para el reino de Granada a finales del período nazarí, muestran una red organizativa parecida a la que pudo haber en Castilla durante el siglo XV. Y por si la amplia extensión de los distritos judiciales fuera poco, a los cadíes y alcaldes se les encomendaban embajadas y misiones diplomáticas, en las que su prestigio social quedaba bien patente ${ }^{30}$, pero que les alejaban de sus ocupaciones principales.

\subsection{Control de los bienes habices de la comunidad mudéjar} y gestión de los bienes de viudas y huérfanos

El alcalde gestionaba los intereses de los más necesitados de la comunidad (huérfanos, viudas, y bienes sin propietario), tal como reconocen los privilegios reales confirmados a Murcia por Juan II:

Otrosy tengo por bien e mando que quando algunos moros finaren en el lugar e fuere sabido que an herederos e sus herederos no fueren y, e quel alcallde moro tenga en fieldad los bienes que aquellos herederos deven heredar en tal manera que sy fasta un año vinieren que ayan aquellos bienes, e sy fasta un año no vinieren herederos del finado, que dende en adelante que los dichos bienes sean dados a mi o a quien lo oviere de aver por mi, e quel alcalle moro que los resçiba con escripto e con recabdo ${ }^{31}$.

29 Concretamente, los vecinos de Huércal y Overa se trasladaban a Vera para que el cadí de esta ciudad hiciera sus autos judiciales, conociese pleitos civiles y para otorgar sus escrituras. Este cadí había sido nombrado por el de Granada. Sin embargo, los vecinos de Lorca reclamaban que las villas de Huércal y Overa también habían tenido cadíes designados por el cadí supremo, lo que no parece aceptable, aunque sí es posible que allí hubiera algún alfaquí para redactar ciertas escrituras. También era posible que los cadíes se desplazasen por el reino para administrar justicia. Arcas Campoy, M., «Noticias sobre el cadiazgo», 207, 209; "Cadíes y alcaides de la frontera oriental nazarí», Al-Qantara, XX (1999), 489-490.

${ }^{30}$ Aunque en Castilla no se ha conservado documentación de ninguna embajada de un alcalde mayor de los moros, pensamos que puede extrapolarse, puesto que en Aragón y Granada eran muy comunes, a la espera de que nueva documentación lo confirme. Calero Secall, M. I., «Rulers and Qāḍīs», 250-251 y «La justicia», 409; Salicrú i Lluch, R.: Documents per a la història de Granada del regnat d'Alfons el Magnànim (1416-1458), Barcelona, 1999, 28-35.

31 Abellán Pérez, J., Documentos de Juan II. CODOM. XVI, Murcia-Cádiz, 1984, 59. 
En este sentido debe entenderse la actuación de Muhammad al-Qaysī respecto al nombramiento de Alí de Montejo en Sepúlveda. Lo que no queda claro es quién presenta ante el alcalde mayor la querella relativa a la falta de protección de huérfanos y viudas que es la que le moviliza, en última instancia, a dar el cargo a Montejo. La discusión de un caso concreto de inventario de los bienes de una viuda y sus huérfanos, que no se pudo hacer por falta de alcalde, se presenta en la forma característica del derecho malikí. ¿Fue alguien a querellarse ante el rey por esta razón? Porque lo que parece claro es que, hasta ese momento, los musulmanes de Sepúlveda han acudido a maestre Yça de Segovia a resolver sus causas, y quieren seguir acudiendo a él, por lo que no reciben a Alí de Montejo a pesar de su carta de nombramiento. Sin duda, el hecho de que en Sepúlveda hubiese sólo «esos pocos de moros» condicionó su subordinación a una circunscripción jurídica más importante, la de Segovia. Y, tal como supone Torres Fontes, ese alcalde de Segovia debe ser precisamente Yça Gidelli, autor del Breviario sunní, que era alfaquí y muftí de la ciudad, y reunía por tanto las condiciones para ser un juez delegado. La decisión final, a favor de los criterios de la aljama de Sepúlveda, manifiesta la importancia del acuerdo de la comunidad local a la hora de recibir a sus alcaldes, y la autoridad efectiva del alcalde mayor de las aljamas sobre los musulmanes que viven allí, sin injerencias del rey o los señores.

\section{Unicidad o diversidad}

Precisamente una de las condiciones principales para el ejercicio de la judicatura, según la escuela malikí, era la unicidad. En palabras de Carmona ${ }^{32}$, «la justicia del cadí siempre ha sido ejercida por un juez único, pues el sistema colegiado sólo se aplica en la justicia extraordinaria de los mazālim». Aun así, a veces se dan casos de doble cadiazgo en el mundo islámico, como en el siglo IX bajo los Aglabíes en Ifrīqiya ${ }^{33}$. Cuando se planteó el pleito entre Belvís y Xarafí ambos debían ser muy conscientes de que su resolución suponía que sólo un

${ }^{32}$ Carmona, A., «Le malékisme», 148

${ }^{33}$ Se trata de un caso algo diferente, puesto que cada cadí pertenecía a una escuela jurídica diferente. Agradezco esta información a Maribel Fierro. 
candidato podía triunfar. Resulta extraño, y dice mucho sobre lo complejo de la situación el que Farax de Belvís se aviniera a un acuerdo territorial, cuyos términos lamentablemente no fueron transcritos en ninguno de los pleitos que tuvieron lugar entre ambos personajes. En principio, Belvís conservaba la alcaldía mayor del reino y especialmente Guadalajara, mientras que Abrahen Xarafí recibía la jurisdicción sobre las aljamas de Ágreda y Sevilla, renunciando optar por la alcaldía general:

\begin{abstract}
por que aunque verdad fuera quel fuera reçibido en la çibdad de Sevilla y en la villa de Agreda por alcalde mayor de los moros, que aquello fuera por conçierto $e$ ygoala que entre el dicho don Abrahen Xarafy e el dicho su parte pasaran para que el dicho su parte fuese alcalde mayor en la çibdad de Goadalajara e en otros lugares e el dicho don Abrahen Xarafy en la dicha çibdad de Sevilla e villa de Agreda, e que renunçiara en el dicho su parte todo qualquier derecho que a la dicha alcaldia tuviese e prometiera de non le pedir nin demandar sobre ello, lo qual se ofreçio a provar e juro que lo susodicho venia nuevamente a su notiçia, e dixo que la merçed por mi la reyna fecha seyendo prinçesa non le aprovechava por que en aquel tiempo el dicho su parte e su padre poseyan la dicha alcaldia por merçed que della tenian del señor rey don Enrique nuestro hermano ${ }^{34}$.
\end{abstract}

En Granada, al-Bunnāhī había escrito ya sobre la duplicidad de cadíes en una sola ciudad en el siglo anterior, citando a Yahyà $b$. Mas' ${ }^{c} \bar{d}{ }^{35}$ : «lo que dan los textos como permisible es que haya dos cadíes o más en una sola población pero cada uno con su jurisdicción y autonomía propia en su distrito y, añade, que si las dos partes interesadas en un litigio disputan a propósito de elegir cadí se echa a suertes». Desconocemos si en el caso castellano se mantenía la costumbre de sortear la alcaldía. Más bien, este concierto o iguala reconocía unas esferas de influencia justificadas no por la donación de Isabel (en el pleito se recuerda constantemente que no era atribución suya este nombramiento) sino por las redes de la familia Xarafi, que muy probablemente mantendría posesiones en Sevilla si aceptamos su ori-

${ }^{34}$ ARCV, RCE, c. 29, 1, f. 7.

35 Cit. Calero Secall, M. I., «La justicia», 388.

${ }^{36}$ Molénat, J. P., «Une famille de l'élite», 769. En «À propos d'Abrahen Xarafí...», 182, Molénat interpreta que Belvís sólo tenia la alcaldía «local» de Guadalajara, y no la de todo el reino, lo que no corresponde a la información que venimos manejando para este artículo. Igualmente, no significa nada el que uno y otro firmen sentencias en años diferentes, porque en 1489, Farax de Belvís todavía puede intitularse alcalde mayor de las aljamas sin competencia, ya que los pleitos aún no se han fallado, y en 1493, ocurre lo 
gen andaluz, como defiende Molénat ${ }^{36}$. La firma de ligas o convenios entre alcaldes y alfaquíes como cabeza de las aljamas, tenía precedentes. Por ejemplo, el texto de un acuerdo firmado en la zona fronteriza de Aragón, concretamente en Calatayud, sobre el ejercicio del cargo de alfaquí por dos miembros de la comunidad, Brahem Alahemi y Ali Cetina, dirimiendo las desavenencias que hubiera entre ellos y estipulando cuidadosamente qué servicios debían realizar cada uno para la aljama, cuándo y cuánto se les pagaría por ello ${ }^{37}$. Quedaría por saber qué tenían que decir las aljamas correspondientes a este arreglo, y especialmente interesante sería saber la reacción de Sevilla. Esta ciudad ya tenía un alcalde, maestre Çayde Blanco, quien además de ser herrero y alcalde mayor de la aljama, poseía tres casas en distintas collaciones ${ }^{38}$. Aunque en un primer momento pudieron entrar en conflicto, al coincidir los dos en la alcaldía de Sevilla, Çayde Blanco debió también caer bajo la jurisdicción de Xarafi después de que éste ganara los pleitos y se erigiera como el alcalde mayor indiscutible de las aljamas, puesto que en 1499 le presenta al «alfaquí Xarafi» un pleito procedente de Sevilla para que dé fe de que ha recibido los documentos 39 .

\section{Factores de ruptura}

a) Participación de autoridades cristianas en el nombramiento de los alcaldes mayores o de sus lugartenientes

La intervención de la nobleza en el nombramiento de los cargos de las aljamas musulmanas y judías es un fenómeno que se repetirá a lo largo de todo el siglo XV, pero que ya cuenta con precedentes durante la etapa islámica del cadiazgo ${ }^{40} \mathrm{y}$, a este respecto, no supone en abso-

mismo con Xarafi, pues entonces ya ha muerto Belvís, y las sentencias ya han sido a favor suyo.

37 García Marco, F. J., Las comunidades mudéjares de Calatayud, 245-246.

38 Valoradas en más de 10.000 maravedís cada una, aparte de la posesión de otros bienes y el cobro de las armas que fabrica, todo ello entre 1484 y 1502 . Wagner, K., Regesto de documentos del Archivo de Protocolos de Sevilla referentes a judios y moros, Sevilla, 1978, 47-48, 58, 64, 75, 82-85, 97.

39 Wagner, K., Regesto, 79-80.

40 Agradezco a Maribel Fierro esta observación. 
luto una ruptura. Sin embargo, las propias comunidades mudéjares y judías lo vieron así, puesto que la injerencia era de un cristiano, una persona externa a la comunidad y cuya autoridad no podía de ninguna forma imponerse a ésta. La intervención de poderosos personajes cristianos y sus redes de influencia en la designación de los cargos comunitarios, llevó a judíos y musulmanes a presentar sus quejas ${ }^{41}$. Así ocurrió en la concesión de la alcaldía de Sepúlveda a Alí de Montejo, gracias al camarero mayor del rey, Pedro Carrillo, o con los delegados reunidos en 1432 por Abraham Bienveniste para acordar un nuevo repartimiento de los impuestos, que se lamentaban de que los rabinos se hicieran con recomendaciones de miembros de la corte para conseguir los oficios de las aljamas.

Sin embargo, las protestas no tuvieron mucho efecto, pues ya hemos comprobado cómo en los casos de Yahya y Farax de Belvís y de Abrahen Xarafí, vuelven a desempeñar un papel principal los grandes personajes del consejo real: el condestable Álvaro de Luna y la familia Mendoza en el primer caso y el arzobispo Carrillo en el segundo.

\section{Nombramientos hereditarios por escrito}

La aparición en las confirmaciones de Farax de Belvís y de Abrahen Xarafí de una cláusula que les permite dejar el cadiazgo en herencia a sus hijos es algo absolutamente insólito en el cadiazgo islámico. El primero en lograrlo parece que fue Belvís que, para asegurarse frente a una posible apelación de Abrahen Xarafí, consiguió que el cargo pudiera pasar a su hijo Yahya. He aquí, pues, una ratificación por escrito de la costumbre de hacer el cargo de alcalde hereditario para otro miembro de la familia, aunque desconozcamos, como veremos más adelante, si la transmisión se hacía efectiva en el testamento de Farax de Belvís. Sabemos que su pariente valenciano, Mahomat de Bellvís, dejó el cargo a su hijo Alí en su lecho de muerte, en $1484{ }^{42}$. Este tipo de documentación falta en el reino de Granada, donde sólo

${ }^{41}$ Esta situación fue observada por Kriegel, Les juifs à la fin du Moyen Age, 113-115 en el caso de las aljamas judías, y tiene su paralelo en las mudéjares, según demostraremos en este mismo trabajo.

${ }^{42}$ Meyerson, M., op. cit., 102. ARV, Bailía General, 1157, 696r-698v. 
se observan los rastros de la patrimonialización del cargo en las listas de cadíes supremos, que evidentemente presentan a personajes de la misma familia ${ }^{43}$.

\section{Atribución de la jurisdicción civil y criminal}

Una de las diferencias básicas en el ejercicio de la judicatura islámica en Castilla, Aragón y Granada es la atribución de la jurisdicción civil y criminal. Mientras que los sultanes nazaríes se arrogan el ejercicio de la jurisdicción criminal, dejando a los cadíes sólo la civil 44 -como responsabilidad en matrimonios, contratos, etc.- , los alcaldes mudéjares castellanos son una «fosilización» de períodos en los que los alcaldes mayores (cadíes) gozaban de ese tipo de jurisdicción. En cambio Aragón sigue el modelo granadino, pues son el rey y el batlle los que tienen la jurisdicción criminal ${ }^{45}$. Lo mismo ocurre con los territorios que se conquistan durante la guerra de Granada, que se siguen rigiendo por el sistema granadino, a petición de sus propios cadíes: Alí Dordux llega a plantearles a los Reyes Católicos que son ellos y no él, quienes deben ejercer la justicia criminal sobre los mudéjares granadinos ${ }^{46}$. El hecho de que se reconozca a Xarafí poder sobre los alguaciles y la ejecución de la sentencia es, por lo tanto, un uso propio de Castilla, basado probablemente en una influencia del derecho cristiano tanto romano como de los fueros ${ }^{47}$. El problema planteado a la hora de aplicar penas capitales quizá se solucionó con la difusión de penas pecuniarias ${ }^{48}$. Hubo reiterados intentos por parte de algunos monarcas castellanos por limitar el ejercicio de la jurisdicción criminal, sobre todo durante los reinados de Juan I y Enrique III,

${ }^{43}$ Calero Secall, M. I., «Cadíes del reino nazarí de Granada», 11 y «La justicia», 385-386.

${ }^{44}$ Calero Secall, M. I., «La justicia», 406-407.

${ }^{45}$ Boswell, J., The Royal Treasure.

${ }^{46}$ Ladero Quesada, Los mudéjares en tiempo de Isabel I, 118-119.

$47 \mathrm{Al}$ menos esta influencia fue recogida por la comunidad judía, y también sabemos que en Granada se concedía gran importancia a la práctica, la costumbre y el uso local. Hasta que la aplicación del derecho por parte de las comunidades mudéjares no esté mejor estudiada, será difícil aclarar este punto. Baer, Y., Historia de los judíos en la España cristiana, Barcelona, 1998, 355 y Calero Secall, M. I., «La justicia», 369.

48 Así ocurre entre los judíos, que gozan del mismo privilegio. Baer, Y., Historia de los judios, 355, 362-363. 
pero parece que las aljamas consiguieron recuperar esta capacidad, a juzgar por los términos en que se expresan los documentos correspondientes al siglo XV.

\section{El tribunal de apelación}

Una transformación importante en la figura del alcalde es la que supone que se constituya como juez de apelación para todos los casos juzgados por sus lugartenientes - en caso de que la apelación sea contra una sentencia suya, sólo podrá interponerse ante los propios reyes o su audiencia-. Esta figura no existe en el derecho islámico, en el que todos los jueces tienen la misma categoría, aunque los cadíes de Granada intentaron acaparar el poder el supervisar a todos los demás cadíes ${ }^{49}$. Más adelante, el rey proveerá de un juez de apelación cristiano a aquellas comunidades que voluntariamente o presionados por el concejo, renuncian a su prerrogativa de tener un alcalde musulmán ${ }^{50}$.

\section{Conclusiones}

Creemos haber demostrado a lo largo de estas páginas que la organización judicial islámica se mantiene en Castilla durante el período mudéjar, aunque se verá modificada en algunos de sus aspectos. El juez mudéjar o alcalde mayor de las aljamas mantiene su designación por el rey, la unicidad de su cargo, su extracción social de las familias mejor situadas económica y políticamente de la élite mudéjar (no sólo castellana sino también aragonesa) y todas las atribuciones del cargo, incluso alguna más que sus colegas granadinos, cuya labor se ve limitada por la justicia del sultán. En ningún momento parece existir ninguna dependencia de los alcaldes mudéjares respecto a los cadíes granadinos.

Las modificaciones principales se producen a la hora de la intervención de las autoridades cristianas en el nombramiento de los alcal-

49 Calero Secall, M. I., «La justicia», 371, 375.

50 Véase Echevarría Arsuaga, A., «Las aljamas mudéjares castellanas en el siglo XV: redes de poder y conflictos internos», Espacio, tiempo y forma. Sección III-Historia Medieval, 14 (2001), 93-112. 
des mayores; al reflejarse por escrito la patrimonialización del cargo, común a todas las instancias de la administración del estado castellano, a la atribución de la jurisdicción civil y criminal, al contrario que sus contemporáneos granadinos y aragoneses, $\mathrm{y}$ a la adición de una función de juez de apelación que no existía en época islámica. Las últimas investigaciones arrojan nueva luz sobre las familias que ostentaron el cargo y sus redes de influencia en las aljamas mudéjares, y nos permiten suponer un avance de la investigación al respecto en los próximos años.

\section{RESUMEN}

Este artículo trata de estudiar la evolución de la figura del alcalde mayor de las aljamas de Castilla a partir de la institución del cadiazgo de la comunidad islámica (qädī al-qudãt) modificada por el paso del tiempo y la intervención de las autoridades cristianas. Para ello se analizan las familias que desempeñaron este oficio en Castilla, todos ellos pertenecientes a la élite político-militar, comercial y jurídica de las aljamas mudéjares. La institución de la alcaldía mayor de las aljamas del reino, estudiada como algo excepcional por Torres Fontes, no lo es tanto, y encaja perfectamente en la estructura organizativa de las aljamas y en las luchas internas por el poder que se gestan en ellas. A partir de ahí nos concentramos en el estudio de los elementos de continuidad y ruptura que se manifiestan en la institución de la alcaldía mayor de los moros respecto al cadiazgo islámico.

\section{SUMMARY}

This article focuses on the evolution of the major authority of the aljamas in Castile as heir to the Islamic $q \bar{a} \bar{d} \bar{l}$ al-qudatat, head judge of the community. This institution was modified along the centuries and due to the intervention of Christian authorities. First, the families who undertook this office are analysed. All of them were members of the Mudejar military, commercial or juridical elites in Castile. The alcaldia mayor de las aljamas, an institution studied by Torres Fontes as exceptional, is more common than it was thought, and matches perfectly the structure and organization of the aljamas, while it causes some bitter struggles for power inside them. The last part is devoted to the continuities and disruptions which took place during the transition from the Islamic qudatt to the later alcalde. 